\title{
The Role of the Regulator in the Field of Safety Culture to Shun Nuclear Accident
}

\author{
Magy Kandil \\ Egyptian Nuclear and Radiation Regulatory Authority (ENRRA), Cairo, Egypt
}

Email address:

magy_kandil@yahoo.com

To cite this article:

Magy Kandil. The Role of the Regulator in the Field of Safety Culture to Shun Nuclear Accident. Journal of Energy and Natural Resources. Vol. 7, No. 1, 2018, pp. 1-11. doi: 10.11648/j.jenr.20180701.11

Received: August 30, 2017; Accepted: January 12, 2018; Published: January 25, 2018

\begin{abstract}
Safety is the primary purpose of the regulatory body, Regulator plays a significant role in the field of nuclear safety even though the prime responsibility for safety belongs to the operator, the regulator which actually decides what is considered to be safe. In order to effectively implement the international principle of high level of nuclear safety, nuclear safety culture should be clearly named as an objective in international nuclear legal acts and the regulator's responsibility for promotion of nuclear safety culture should be established. What is more difficult for the regulator is finding the right balance of firmness but fairness in dealing with the operator. In addition to enforcing safety regulations, the regulator should have a positive effect on the operator's safety culture. The regulator can promote safety culture in the operator's organization just through the mere fact of placing it on the agenda at the highest organizational levels.
\end{abstract}

Keywords: Nuclear Safety, Nuclear Power Plant, The Regulator, Nuclear Safety Culture, Levels of the Safety Culture, Safety Culture Principals

\section{Introduction}

It is well know that nuclear power plant operations are complex and tightly coupling, international recommendations assure the clear significance of people related problem, deficiencies in the organizations structures and management problems. Then things like: human factors, management involvement, regulatory environment, institutional structures, became apparent as bearing a lot of responsibility in avoiding failures. Consideration to human factors and managerial aspects must be taken into account in a new technology and to be carefully studied.

The plant owner's/operator's first, foremost, and overriding responsibility is to ensure the safe operation of its plants. The owner/operator has other responsibilities, of course, including the provision of a reliable supply of electric power and protection of plant investments. A major accident can challenge the continued viability of an operating company, and so owners/operators could elect to adopt stricter safety standards and management practices than required by regulations.

The ultimate responsibility for nuclear plant safety and environmental protection resides with the plant's owners, managers, and operating staff and the agencies that regulate them. Five decades of nuclear plant operating experience demonstrate clearly that it is not possible to anticipate all combinations and permutations of operating conditions that can occur at a nuclear plant. Consequently, safety cannot be achieved only through rules, regulations, hardware design, and operating procedures. It also requires onsite intelligence, learning, and decision making by plant operating staff. More importantly, it requires "commitment by leaders and individuals to emphasize safety over competing goals to ensure protection of people and the environment" [1].

The nuclear industry and its regulators can work together to promote nuclear safety, especially through the development of common understandings of problems and potential solutions. However, safety can be compromised if plant owners/ operators adopt a compliance-only operating philosophy. On the other hand, regulators can become ineffective or even captured by the nuclear industry if independence is lost. Both of these situations can weaken the industry and the regulator's responsibilities to protect the public interest.

The biggest danger in trying to understand culture is to oversimplify it in our minds. It is tempting to say that culture 
is just "the way we do things around here", or "our basic values", or "our rituals", and so on. These are all manifestations of the culture, but none is the culture at the level that culture matters. A better way to think about culture is to realize that it exists at several "levels" and that we must endeavor to understand the different levels, but especially the deeper levels [2].

There is international acceptance by the nuclear power community that a strong nuclear safety culture needs to be adopted universally: by senior management of organizations operating nuclear power plants, by individuals who work in those plants, and by regulatory bodies and other organizations that set nuclear power policies.

Additionally, Safety culture refers to the attitudes, behaviors, and conditions that affect safety performance and often arises in discussions following incidents at nuclear power plants. As it involves both operational and management issues, safety culture is a sensitive topic for regulators whose role is to ensure compliance with safety requirements and not to intervene in management decisions. The role of regulators is to oversee licensee operations to ensure that licensees comply with safety requirements and not to intervene in management decisions until a serious incident has occurred or is imminent. The licensees retain full responsibility for safe operation of their plants. Safety culture is a sensitive issue for the regulator because it is crosscutting, involving both operational and management issues. If regulators were to be more proactive toward safety culture, as some critics suggest they should be, regulators would have to focus on those attributes of safety culture that are performance-based in order to avoid undue interference in licensee management.

The objective of this paper is to provide an overview of proposed safety culture attributes and to discuss the role of regulatory body in the field of the safety culture by determining the level of the safety culture and how to promote and assess safety culture.

\section{The Concept of Nuclear Safety}

In order to understand the role of the regulator in the field of nuclear safety, it is important to understand the concept of nuclear safety itself. The fundamental safety objective is to protect people and the environment from harmful effects of ionizing radiation. The restriction of the likelihood of events that might lead to a loss of control over a nuclear reactor core, nuclear chain reaction, radioactive source or any other source of radiation is one of the measures to ensure that facilities are operated and activities conducted so as to achieve the highest standards of safety that can reasonably be achieved. 1 In other words, the "restriction of the likelihood" is the base of the nuclear safety.

Nuclear safety consists of 10 safety principles:

1. Responsibility for safety;

2. Role of government;

3. Leadership and management for safety;

4. Justification of facilities and activities;
5. Optimization of protection;

6. Limitation of risks to individuals;

7. Protection of present and future generations;

8. Prevention of accidents;

9. Emergency preparedness and response;

10. Protective actions to reduce existing or unregulated radiation risks.

These principles are the foundation of the nuclear safety as they are to large extent the basis for the obligations of the Parties under the Convention on Nuclear Safety. Responsibility for safety means that the prime responsibility for safety must rest with the person or organization responsible for facilities and activities that give rise to radiation risks. It also means that the operator retains the prime responsibility for safety throughout the lifetime of facilities and activities, and this responsibility cannot be delegated. Other groups, such as designers, manufacturers and constructors, employers, contractors, and consignors and carriers, can also have legal, professional or functional responsibilities with regard to safety. This principle is significant in understanding the role of the regulator in the big picture of nuclear safety. Regardless of how active or important regulator is in the field of nuclear safety, it is the operator which actually takes physical safety measures and is responsible for the outcomes of the latter.

\section{Features of Safety Culture}

\subsection{Safety Culture Definitions}

Safety Culture means, it is all that is implemented to: Ensure your safety during operations, Correctly sort the waste, Discharge radioactivity into nature and Ensure the functionality of the plant, in other words, avoiding any deviation from what is planned. It is all the characteristics and attitudes that, in organizations and individuals, ensure that the issues relating to the safety of nuclear plants are accorded, as a priority, the attention they deserve due to their importance.

As it is said in the INSAG-4 [3] the safety culture has two general components. The first is the necessary framework within an organization and the responsibility of the management hierarchy, the second is the attitude of the staff at all levels in responding and benefiting from the framework. Thus the management of safety and the involvement of staff are key factors achieving a good safety culture. On the other hand it is recognized that safety and quality are synonymous attributes in the good plant performers [2], [3].

\subsection{The Safety Culture Principles}

The main safety culture principles can be summarized in:

1. Looking toward excellence in nuclear safety matters.

2. Achieving optimum reliability.

3. Placing adequate human and economic resources.

4. Establishing quality in organization structure and plant operation. 
5. Incorporating technology innovation.

The global objectives is to achieve:

1. Safety improvement.

2. Optimum efficiency.

3. Quality measures.

4. Innovation processes.

In all types of activities, for organizations and individuals at all levels, attention to safety involves many elements: Individual awareness, knowledge and competence, commitment, motivation through leadership, supervision and responsibility.

\section{Cultural Principles}

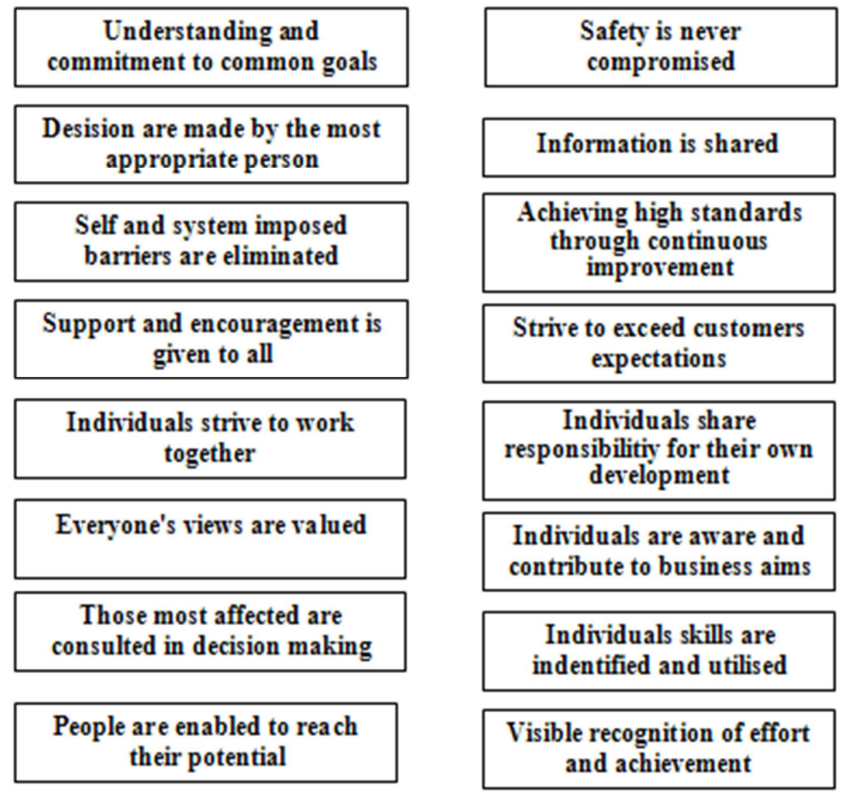

Figure 1. Illustrates the major components of safety culture Principals.

\subsection{Safety Culture Characteristics}

All various definitions of Safety Culture (SC) indicate that $\mathrm{SC}$ can be characterized by five attributes as shown in Figure 2. These attributes include the following core meaning is [5]:

1. Prioritize safety as a shared value within an organization. In order to work with safety culture, organizations should spend sufficient time to reach a common understanding since the concept by its nature is difficult to explain in a few sentences.

2. Safety culture does not exist in isolation and is influenced by the prevailing organizational climate or culture. It is important that the organization culture be supportive of safety and, particular, that it should encourage the appropriate behavior, attitudes and values on the part of the employees [6].

3. Culture is a dynamic concept that encompasses everything that happens in an organization. It affects what we do, what we think, and what we make sense of - it is our collective understanding of reality. Therefore, to eliminate ambiguity, it is valuable for an organization to share perspectives about what safety culture encompasses in day to day work-related tasks.
4. Perform an early assessment of national and local cultural attributes in relation to safety awareness and attitudes toward risk. National and local cultures are the context within which safety culture must be developed. Efforts should be directed at strategies for countering attributes that would hinder the development of a strong safety culture.

5. Assign leaders with an understanding of and commitment to developing a strong safety culture. Such leaders have the courage to promote organizational learning by questioning established practices, revitalizing complacent organizations, and helping those who are not familiar with best practices.

6. Engage external expertise in the early phases, specifically in the areas of safety, safety culture, human performance, organizational design, management system design, and regulatory development

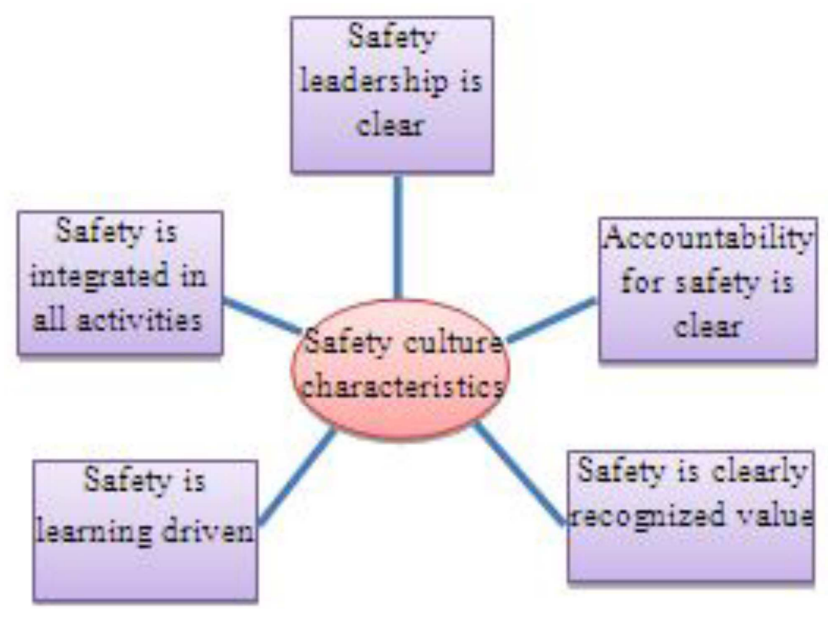

Figure 2. Safety culture attributes.

\section{General Safety Requirements on Governmental, Legal and Regulatory Framework for Safety}

There are many IAEA Safety Requirements publications which have a general scope of establishing the basic requirements for legal and governmental infrastructures for nuclear, radiation, radioactive waste and transport safety. However, due to the objectives of the research I would like to pay specific attention to the requirements for legal and governmental responsibilities in respect to the safety of nuclear facilities.

The Requirements for the Legislative and Governmental Mechanisms of Sates

They are established:

1. Legislative and statutory framework to regulate nuclear safety must be established; the regulatory authority is responsible for establishing safety principles, criteria, regulations and guides;

2. Independence of regulatory authority must be assured;

3. Responsibility for authorization, regulatory review, 
assessment, inspection and enforcement shall be assigned to the regulatory authority;

4. Adequate staffing and financial resources for the regulatory authority must be ensured;

5. No other responsibility shall be assigned to the regulatory body which may jeopardize, or conflict with, its responsibility for regulating safety.

These requirements could be considered as the basic elements of the safety control mechanism - legal framework, independent and resourceful authority and regulative functions.

The regulative functions mentioned above could be divided into three blocks: rights, responsibilities and the additional functions of the regulatory authority.

The Rights

The rights that are assigned to the regulatory body. They are established:

1. to develop safety principles and criteria;

2. to establish regulations and issue guidance;

3. to require any operator to conduct a safety assessment;

4. to require that any operator provide it with any necessary information, including information from its suppliers, even if this information is proprietary;

5. to issue, amend, suspend or revoke authorizations and to set conditions;

6. to require an operator to perform a systematic safety reassessment or a periodic safety review over the lifetime of facilities;

7. to enter a site or facility at any time to carry out an inspection;

8. to enforce regulatory requirements;

9. to communicate directly with governmental authorities at higher levels when such communication is considered to be necessary for exercising effectively the functions of the body;

10.to obtain such documents and opinions from private or public organizations or persons as may be necessary and appropriate;

11.to communicate independently its regulatory requirements, decisions and opinions and their basis to the public;

12.to make available, to other governmental bodies, national and international organizations, and to the public, information on incidents and abnormal occurrences, and other information, as appropriate;

13.to liaise and co-ordinate with other governmental or non-governmental bodies having competence in such areas as health and safety, environmental protection, security, and transport of dangerous goods; and

14.to liaise with regulatory bodies of other countries and with international organizations to promote cooperation and the exchange of regulatory information.

The Responsibilities

The main responsibilities of the regulator concerning nuclear safety. They are established:

1. to shall establish, promote or adopt regulations and guides upon which its regulatory actions are based;
2. to review and assess submissions on safety from the operators prior to authorization and periodically during operation;

3. to provide for issuing, amending, suspending or revoking authorizations;

4. to carry out regulatory inspections;

5. ensure that corrective actions are taken if unsafe or potentially unsafe conditions are detected;

6. take the necessary enforcement action in the event of violations of safety requirements.

\section{Certain Additional Functions}

Certain additional functions, ensuring, however, that any conflict with its main regulatory functions is avoided and that the prime responsibility of the operator for safety is not diminished. The example list provides these additional functions:

1. independent radiological monitoring in and around nuclear facilities;

2. independent testing and quality control measurements;

3. initiating, coordinating and monitoring safety related research and development work in support of its regulatory functions;

4. providing personnel monitoring services and conducting medical examinations;

5. monitoring of nuclear non-proliferation;

6. regulatory control of industrial safety.

From pervious dissection, the main role of the regulatory body in the field of nuclear safety could be described in a following way: the regulator creates "the rules of playing safe" and controls how the operator follows them, while the operator has to play by those rules and prove it the regulator on regular basis. In this context, two terms should be clarified - responsibility for safety and responsibility for assuring safety. The earlier, responsibility for safety primarily falls under the operator. This responsibility essentially implies that the operator is implementing legal framework, technical requirements and is taking all other necessary measures in order achieve proper operating conditions, as well as prevent accidents and protect workers and environment from undue radiation hazards. Responsibility for assuring safety, on the other hand, means that the regulator is setting the legal and technical bars of what is considered to be safe and takes all necessary measures in order controlling how the operator fulfills its obligations. Due to all that, "the game" is played by the regulator's rules, which means that while the operator is responsible for the actual safety, it is the regulator who decides what is considered to be safe. [1]

\section{Role of the Regulator in Nuclear Safety Culture}

Safety is the primary purpose of the regulatory body. What is more difficult for the regulator is finding the right balance of firmness but fairness in dealing with the operator. In addition to enforcing safety regulations, the regulator should have a positive effect on the operator's safety culture. The 
regulatory body has a dual role in the field of safety culture promoting safety culture through its own example and evaluating the safety culture of licensees through performance or process based inspections and other methods.

\subsection{The Evaluation of Safety Culture}

For the evaluation of safety culture has presented strategy of the regulatory response. It is based on assumption that early signs of safety problems may be ambiguous, but nonetheless may justify enhanced regulatory attention. Various activities can be used to evaluate an organization's safety culture. These include direct observations, assessments, Causal Factors or Root Cause Analysis, surveys, interviews, review of key safety culture related processes, performance indicator monitoring and trending, and Voluntary Protection Program VPP type assessments [7].

\subsection{The Promotion of Nuclear Safety}

The regulator can promote safety culture in the operator's organization just through the mere fact of placing it on the agenda at the highest organizational levels. The operator's priorities are influenced by those matters regarded as important by the regulatory body. Thus, the regulator can stimulate the development of a safety culture by providing positive reinforcement for good performance and high quality in plant work processes, by encouraging good safety practices, by promoting the examples of operators having a good safety culture, and by recognizing initiatives of industry organizations [6] [8]. The promotion of nuclear safety, however, is the field where big potential could be seen for the regulator to play a significant role.

Firstly, the preamble of the Convention on Nuclear Safety expresses the will to ensure effective nuclear safety culture which means that all necessary measures should be taken in order to achieve high level of nuclear safety culture.

Secondly, promotion of strong nuclear safety culture is established in the Specific Safety Requirements, however, it only requires the operator to implement it.

Thirdly, concept of the regulator's responsibility to promote safety culture already exists in the field of radiation protection. In the International Basic Safety Standards (BSS) [9] it is stated that the Regulatory Authority has a responsibility to require all parties involved to develop a safety culture. According to the BSS, the safety culture includes: individual and collective commitment to safety on the part of workers, management and regulators; accountability of all individuals for protection and safety, including individuals at senior management level; and measures to encourage a questioning and learning attitude and to discourage complacency with respect to safety. Therefore, the latter regulation in the field of radiation protection could be used as an example of how the regulator's role of promoting nuclear safety could be defined in the nuclear safety.

Due to all that, the conclusion could be drawn that there are legal grounds in order to establish regulator's responsibility for promoting nuclear safety culture. There are several positive aspects that the latter responsibility would bring to the table. First of all, such establishment would allow the regulator to harmonize nuclear safety culture on the national level. Besides that, it would encourage the regulator to organize forums and seminars in order to ensure the sufficient exchange of information and learning experiences on the national level, which could be the significant input in developing nuclear safety culture. Finally, establishment of promotion of nuclear safety culture would allow the regulator to do an input in implementing the ground principle of international nuclear law - ensuring and maintaining high level nuclear safety.

As safety culture involves everyone, whose attitude may influence nuclear safety, not only the utility operators but also the regulatory body.

Safety culture cannot be easily regulated and controlled taking into account the fact that it is based on the attitudes, beliefs and other psycho sociological features of the employees. These attributes cannot be strictly documented and measured. However, it probably can be regulated and controlled indirectly. Although safety culture is easy to speak about its importance for nuclear safety, it is very difficult to deal with safety culture itself, to measure, strengthen it or even to try to regulate it.

The relation between safety culture at nuclear power plants and regulatory authority can be defined and discussed in terms of legal requirements, guidance, international standards, routine inspections, discussions, seminars and other measures as shown in Figure 3. Defining and establishing an effective safety culture and recognizing related trends is still a recent initiative, undergoing development and review within operator organizations and regulatory bodies. As more studies are performed and experience is gained in this area, the role of the regulator in promoting and evaluating safety culture will continue to evolve and mature [7].

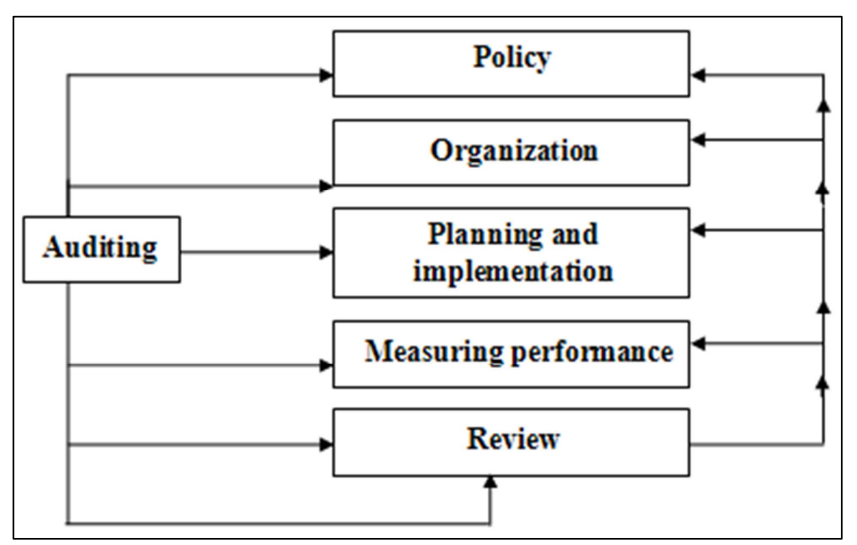

Figure 3. The Role of the regulator for establishing an effective safety culture.

\section{Regulating Safety Culture}

One of the most difficult challenges in assessing the 
safety performance at a nuclear power plant is to recognize the early signs of declining safety performance, before conditions become so serious that regulatory sanctions must be imposed or, worse, a serious incident or accident occurs [9]. Safety culture, probably, cannot be regulated directly, especially if we speak about psycho sociological features of the employees. However, it definitely can be influenced indirectly through the safety culture related issues. When we speak about influence to the safety culture of the licensee, it should be understood that safety culture can be influenced positively or even affected negatively. And in this context competence of the regulatory authority is crucial [6].

The Nuclear Safety Law of a country should include statement regarding the safety culture. It should declare that nuclear facilities operating organizations and other licensees shall ensure high level of safety culture within the organization and its employees. The statement provides a legal basis to describe this understanding in a more detailed way and enables the regulatory authority to control the safety culture related activities [6]. So based on the national legislation, cultural aspects and existing experience in a specific country, safety culture can be regulated in different ways. General requirements can be presented in the top level legislation. More detailed requirements can be presented in the mandatory regulatory documents. And much more detailed safety culture related aspects can be regulated through the non-mandatory guidance type documents. The IAEA standards can be used also as reference requirements or guidance.

\subsection{Safety Culture of Regulatory Body}

Regulation and control of the safety culture related issues cannot be separated from the safety culture of the regulatory authority itself. It should be difficult to understand proper regulation of the safety culture issues if the regulatory authority is not in the position to ensure that the existing regulatory and control practice is based on the proper application of the safety culture understandings. The following issues in this respect can be highlighted [10]:

1. Competency of the regulatory staff. This is a basis for all activities of the regulatory authority.

2. Properly developed internal management system. Properly developed internal management system essentially contributes to the effectiveness of the regulatory authority and efficiency of its employees.

3. Clear, consistent regulatory documents. The quality of the regulatory documents has two important aspects for:

a. The licensee can clearly understand and act based on the explicit regulatory norms,

b. The employees of the control institution can understand and be capable to properly apply the regulatory norms during the safety evaluation and inspection activities.

4. Properly oriented regulatory control, no space should be left for any corruption or private interest elements of inspectors. It can totally destroy the basis for safety culture.

5. Clear and consistent requirements. There are more realistic and frequent problems in this area related to the possible misinterpretation of the regulatory requirements during the inspection or safety evaluation activities.

6. It is difficult to produce perfect regulatory requirements (especially for small countries). Some of the requirements are not explicit enough,

7. Some of the regulations do not cover all necessary safety related issues,

8. And some of the regulations can be simply out-of-date.

9. Proper and fair regulator decision, it happens that inspector can identify that the licensee has violated a regulatory requirement which, actually, do not create any additional value to the safety assurance. The regulatory decisions shall not disorientate the licensee from activities important to safety towards activities important for escape from possible sanctions. The above mentioned points can be abbreviated in the following milestones to provide the basis for proper safety culture regulatory environment [9]:

10. Safety culture of the regulatory authority itself;

11. Proper identification, regulation and supervision of the licensee's safety culture related issues; and

12. Enhancement of the safety culture regulatory and control activities through the possibilities provided by and duties derived from the international cooperation. The nature of the relationship between the regulator and the operator can influence the operator's safety culture at a plant either positively or negatively. In promoting safety culture, a regulatory body should set a good example in its own performance. This means, for example, the regulatory body should be technically competent, set high safety standards for itself, conduct its dealings with operators in a professional manner and show good judgment in its regulatory decisions. Some of the attributes of a good regulatory safety culture are the following [10]:

13. a clear organizational commitment to priority of safety matters;

14. clear lines of responsibility within the regulatory body;

15. a program of initial and continuing training to maintain regulatory staff competence; a personal commitment to safety from every staff member;

16. good communication and co-ordination between organizational units of the regulatory body;

17. clear guidelines for conducting safety reviews;

18. clear guidelines for conducting safety inspections;

19. clear regulatory acceptance criteria;

20. a commitment to timely regulatory decisions;

21.a commitment to regulatory intervention that is proportionate to the safety circumstances; and

22. The use of risk insights in decision-making. 


\subsection{Safety Culture Assessments}

There is no composite measure for safety culture. The changing nature of safety culture makes it unlikely that such a measure will ever be found [9]. So assessing progress in the development of safety culture should be based on identifying the range of indicators that reflect the individual subcomponents of safety culture. Such component includes observable behavior, conscious attitudes and perceptions or beliefs. IAEA safety reports series No.11 [4] gave examples of methods that had been applied to measure these key components as shown in Figure 4.

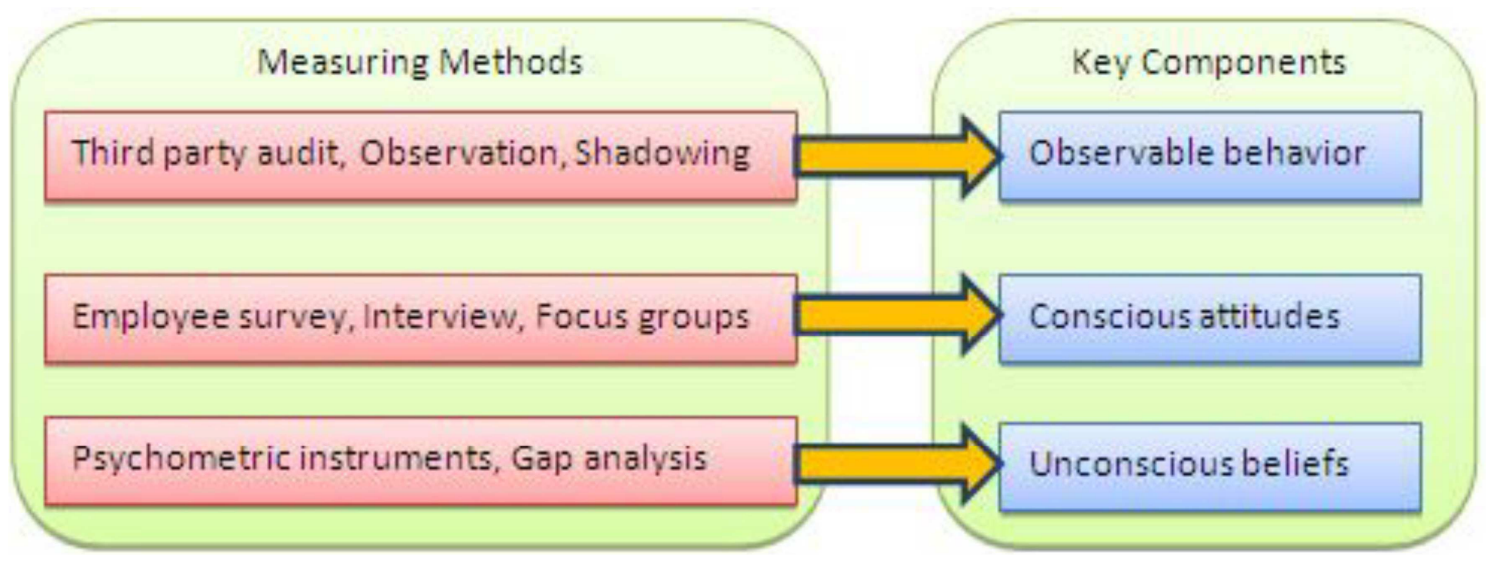

Figure 4. Measuring Methods for Safety Culture Components.

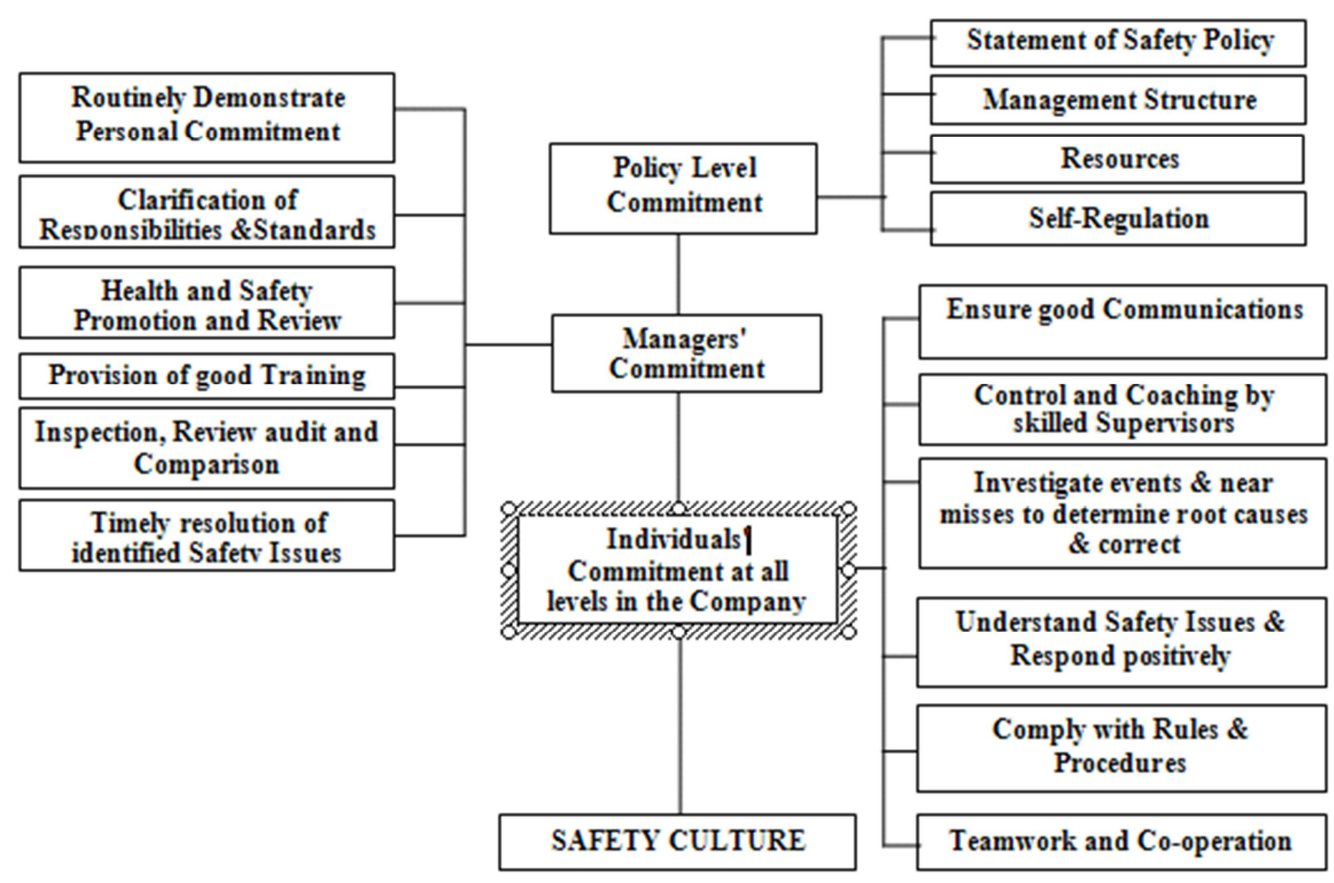

Figure 5. Illustrates a general model evaluation of safety culture.

To facilitate the recognition of declining plant processes and performance, the regulator may perform periodic safety assessments of a facility [7]. This should be a systematic assessment of performance based on coordinated discussions and reviews by the regulatory staff.

The assessment may include the following:

1. Observations by site inspectors and specialist inspectors;

2. Reviews by regulatory safety specialists;

3. Reviews of trends in event reports;

4. Review of the effectiveness of operator's controls to identify, correct and prevent problems. These controls include: safety review committees, root cause analysis programs, corrective action programs, and selfassessment programs;

5. Review of work backlog and delays in implementing prescribed actions;

6. Assessment of day-to-day incidents, which can reveal both organizational weaknesses and inadequate response by individuals; and

Review of operating events to look carefully for safety significant events or conditions that may be precursors to serious accidents. Often it requires an analysis using Probabilistic Safety Assessment (PSA) methodology to fully 
understand the safety significance of a complex event. When the outcome of a safety assessment suggests the onset of declining performance, the regulator may decide upon a special surveillance program for the plant. This could include regulator meetings with plant management and staff to discuss the assessment findings and to better. Lack of a safety culture can lead to operator behavior which breaches multiple barriers of the entire defence-in-depth safety fabric. That is, when the basic safety values, norms and attitudes of an entire organization are weak or missing, then one can have procedures ignored, operating limits exceeded and safety systems bypassed no matter how well they have been designed and built.

Figure 5 illustrates a general model that provides a framework for a high level screening evaluation of safety culture. [1], [2], [3] the model identifies factors that can significantly influence safety culture. The potential benefit of the model is that it prompts consideration of the various influences on safety culture and can highlight areas that warrant more detailed consideration. Although the model is primarily qualitative, it can serve as a basis for a simple screening matrix that provides a quantitative dimension.

\subsection{Strong Safety Culture}

A strong safety culture consists of three major factors, a viable management system; a widely shared awareness of nuclear hazards and widely shared behavioral norms and values. A strong safety culture can be only expected in cases where the management system is implemented into actual behavior not because negative personal or group consequences are feared, but as a result of profound awareness about nuclear hazardous and positive social norms, attitudes and values of management and staff. Poor safety culture comes up in cases where the exiting management system is in itself undeveloped, insufficient or inadequate. Negative attitudes or disruptive informal social norms become predominant.

\section{Detection of Incipient Weaknesses in Safety Culture}

The Symptoms of a Weakened Safety Culture are Regulators have an obvious and legitimate interest in maintaining safety culture, and whilst it may not be practicable or appropriate for them to prescribe a safety culture, they have an important role to play in encouraging organizations to identify, understand and apply positive steps to improving safety culture [11].

\subsection{Organizations Issues}

\subsubsection{Pressure from External Environment}

Many organizations are subjected to increasing economic and market pressures that are forcing them to significantly reduce their cost base. Organizational goals and priorities can change significantly and there is a potential for safety standards and performance to be adversely affected.

\subsubsection{Inadequate Resolution of Problems}

Symptoms of inadequate resolution of problems are repeated crises, significant accumulations of corrective actions, lack of effective managerial prioritization of remedial actions and failure to address the root causes of problems.

\subsubsection{Organizational Insularity}

Organizational insularity can cause safety culture to deteriorate simply because managers come to believe that their safety performance is satisfactory and therefore become complacent.

\subsubsection{Openness}

Open and honest communication between regulator and representatives of an organization is essential if the regulator is to be able to assess and evaluate the safety culture.

\subsection{Regulatory Issues}

\subsubsection{Corrective Actions}

One of the most obvious signs that safety culture is starting to weaken is evidence of a significant accumulation of corrective actions that have not been addressed. The existence of an effective program for self assessment, root cause analysis and corrective action is a positive indication of a good safety culture.

\subsubsection{Patterns of Problems}

Part of the ongoing monitoring of compliance and plant status checks normally carried out by the regulator is the collection of information from varied sources. Repetition of problems usually indicates that the root cause was not identified correctly and that whatever corrective action may have been implemented was not adequate. Information can be collected from formal or informal sources and where possible should be cross checked to validate its accuracy.

\subsubsection{Procedural Inadequacies}

An important element of safety culture is that employees should have confidence in procedures and use them correctly. However, it is essential that the regulator understands the system of regular documentation review and that any deterioration is detected at an early stage. Failure to detect and rectify "out of normal" situations regarding procedures, will lead to plant employees ignoring instructions, losing confidence in documented requirements and probably taking unilateral and unsafe actions.

\subsubsection{Quality of Analysis of Problems and Changes}

Regulators have to be sure that any analysis carried out at the plant follows a systematic, auditable system which will ensure that the correct methods are used, validation performed and the correct solutions defined. The establishment of a review and analysis group at utility with the correct level of experience and qualifications will inspire confidence in the analysis process. 


\subsubsection{Lack or Failure of Independent Nuclear Safety Reviews}

For all safety related proposal and modifications, independent safety assessments should be undertaken by persons other than those who carried out the original work. In a healthy safety culture, these assessments will always have been fully documented and checked for methodological, calculation, and technical accuracy and validity using approved procedures.

\subsubsection{Reality Mismatch}

The state, configuration and condition of the plant must at all times be fully consistent with the claims that are required in support of the safety case must never make demands on plant or personal which are unrealistic or unreasonable

\subsection{Employee Issues}

\subsubsection{Excessive Hours of Work}

Working hours must be formulated and regulated to allow people to perform their duties within reasonable time-scales without imposing undue pressures which can induce unsafe and undesirable consequences.

\subsubsection{Number of Persons not Completing Adequate Training}

Training plays an integral role in the safety culture of an organization, and the regulator would want to be assured that adequate attention is being paid to the quality and applicability of training programs.

\subsubsection{Failure to Use Suitably Qualified and Experienced Persons}

All nuclear plant operations should be carried out by suitably qualified and experienced persons. Whilst this is a basic requirement and even a license conditions for many operating regimes, it obviously can not always be achieved in practice. Such failure tends to show itself in incident and accident event reports that conclude that further training / retraining of personnel is required.

\subsubsection{Understanding of Job Descriptions}

Typically in poor safety cultures, some individuals are not fully aware of the total requirements, responsibilities and accountabilities of their job. This can arise either because job descriptions have not been properly prepared in the first instance or because individuals have not been properly done their employer's expectations.

\subsection{Technology Issues: Plant Conditions}

Plant conditions provide a useful and valuable insight into the general health of an organization's safety culture. Poor housekeeping standards are an indicator of behavior and attitudes which are not likely to be conductive to the development of a sound safety culture.

Other indications are lack of attention to alarms or nor repair of malfunctioning equipment, overdue maintenance work or poor information recording and archiving systems.

\section{Principles for a Strong Nuclear Safety Culture}

\subsection{The Stages of Development Nuclear Safety Culture}

There are three stages of development seem to emerge each displaying a different awareness to emerge the effect on safety of human behavior and attitudes:

Stage I-Safety Based Solely On Rules and Regulations

At this stage, the organization sees safety as an external requirement and not as an aspect of conduct that will help the organization to succeed. The external requirements are those of national governments, regional authorities, or regulatory bodies. There is little awareness of behavioral and attitudinal aspects of safety performance, and no willingness to consider such issues. Safety is seen very much as a technical issue; mere compliance with rules and regulations is considered adequate.

For an organization which relies predominantly on rules the following characteristics may be observed:

1. Problems are not anticipated; the organization reacts to each one as it occurs.

2. Communication between departments and functions is poor.

3. Departments and functions behave as semiautonomous units and there is little collaboration and shared decision making among them.

4. The decisions taken by departments and functions concentrate upon little more than the need to comply with rules.

5. People who make mistakes are simply blamed for their failure to comply with the rules.

6. Conflicts are not resolved; departments and functions compete with one another.

7. The role of management is seen as endorsing the rules, pushing employees and expecting results.

8. There is not much listening or learning inside or outside the organization, which adopts a defensive posture when criticized.

9. Safety is viewed as a required nuisance.

10. Regulators, customers, suppliers and contractors are treated cautiously or in an adversarial manner.

11. Short term profits are seen as all- important.

12. People are viewed as system components'-they are defined and valued solely in terms of what they do.

13. There is an adversarial relationship between management and employees.

14. There is little or no awareness of work or business processes.

15.People are rewarded for obedience and results, regardless of long term consequences.

Stage II-Good Safety Performance Becomes an Organizational Goal

An organization at this stage has a management which perceives safety performance as important even in the absence of regulatory pressure. Although there growing awareness of behavioral issues, this aspect is largely missing 
from safety management methods, which comprise technical and procedural solutions. Safety performance is dealt with, along with other aspects of the business, in terms of targets and goals. The organization begins to look at the reasons why safety performance reaches a plateau and is willing to seek the advice of other organizations.

1. The organizations concentrates primarily on day to day matters, there is little in the way of strategy.

2. Management encourages cross-departmental and crossfunctional teams and communication.

3. Senior managers function as a team and begin to coordinate departmental and functional decisions.

4. Decisions are often centered on cost and function.

5. Managements' response to mistakes is to put more controls in place via procedures and retraining. There is a little less blaming.

6. Conflict is disturbing and is discouraged in the name of teamwork.

7. The role of management is seen as applying management techniques, such as management by objectives.

8. The organization is somewhat open about learning from other companies, especially techniques and best practices.

9. Safety cost and productivity are seen as detracting from one another. Safety is thought to imply higher cost and reduced production.

10.The organization's relationship with regulators, customers, suppliers and contractors is distant rather than close; there is a cautious approach where trust has to be earned.

11. It is important to meet or exceed short term profit goals. People are rewarded for exceeding goals regardless of the long term results or consequences.

12. The relationship between employees and management is adversarial, with little trust or respect demonstrated.

13. There is growing awareness of the impact of cultural issues in workplace. It is not understood why added controls do not yield the expected results in safety performance.

Stage-III Safety Performance Can Always Be Improved

An organization at stage III has adopted the idea of continuous improvement and applied the concept of safety performance. There is a strong emphasis on communications, training, management style, and improving efficiency and effectiveness. Everyone in the organization can contribute. Some behavior is seen within the organization which enables improvements to be made but there is also behavior which acts as a barrier to further improvement consequently. People understand the impact of behavior issues on safety.

The level of awareness of behavior and attitudinal issues is high, and measures are being taken to improve behavior. Progress is made one step at a time and never stops. The organization asks how it might help other companies:

1. The organization begins to act strategically with a focus on the longer term as well as awareness of the present. It anticipates problems and deals with their causes before they happen.

2. People recognize and state the need for collaboration between departments and functions. They receive management support, recognition and the resources they need for collaborative work.

3. People are aware of work or business processes in the organization and help managers to manage them.

4. Decisions are made in the full knowledge of their safety impact on work or business processes as well as on departments and functions.

5. There is no goal conflict between safety and production performance, so that safety is not jeopardized in pursuit of production targets.

6. Almost all mistakes are viewed in terms of work process variability. It is more important to understand what has happened than to find someone to blame. This understanding is used to modify the work process.

7. The existence of conflict is recognized and dealt with by trying to find mutually beneficial solutions.

8. Management's role is seen as coaching people to improve business performance.

9. Learning from others both inside and outside the organization is valued. Time is made available and devoted to adapting such knowledge to improve business performance.

10. Safety and production are seen as interdependent.

11. Collaborative relationships are developed between the organization and regulators, suppliers, customers and contractors.

12. Short term performance is measured and analyzed so that changes can be made which improve long term performance.

13. People are respected and valued for their contribution.

14. The relationship between management and employees is respectful and supportive.

15. People are aware of the impact of cultural issues, and these are factors considered in key decisions.

16. The organization rewards not only those who produce but also those who support the work of others. People are also rewarded for improving processes.

Irrespective of the size of the organization, a prerequisite for the development of a good safety culture is the visible commitment of the person or persons responsible for leading the organization or group.

\subsection{Learning Process}

The process for the development of safety culture can be assisted by the use of a learning process within an organization. A simple model based on the Kolb learning cycle [11], [12] is shown in Figure 6. A person or organization learn by reflecting on what they have experienced, formulating concepts and ideas for change while continuing existing best practice. The implementation of such concepts and ideas is intended to improve performance and there by modify future experience. At an appropriate time this modified experience can itself be reviewed and lessons learned. 


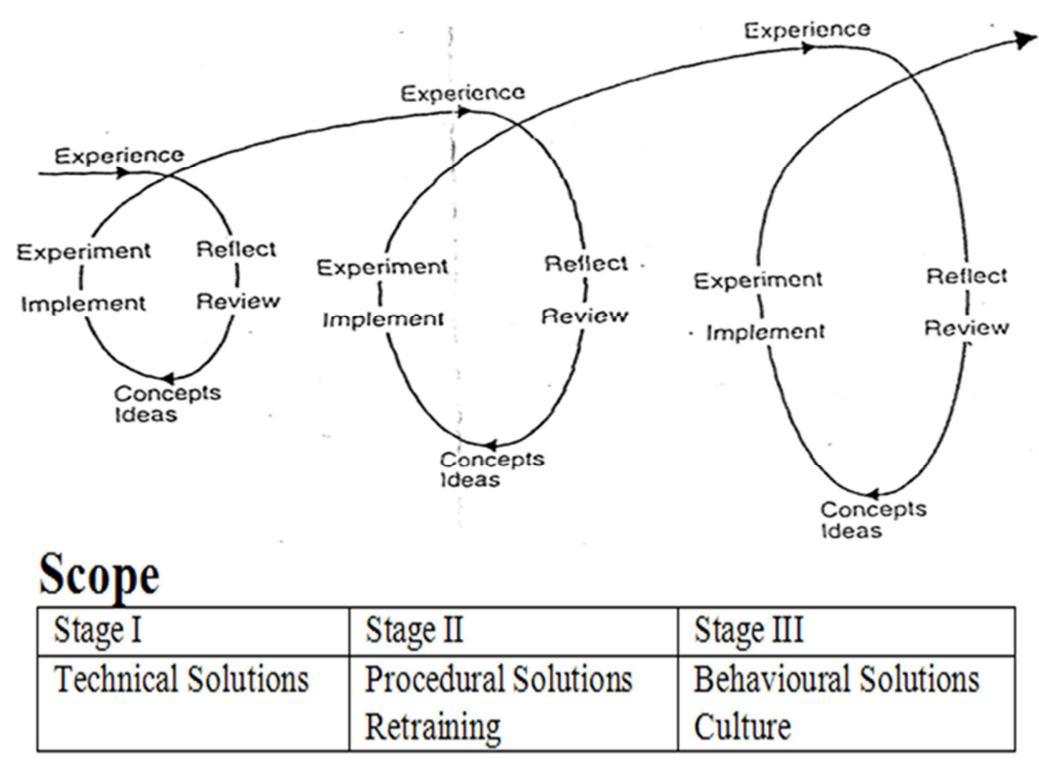

Figure 6. Simple model of organizational learning (after KOLB).

\section{Conclusion}

A good safety culture has a positive impact upon an organization's quality, reliability, competitiveness and profitability. So evaluation of the organization behavior and safety culture, at the time of planning, construction, and operation has important contribution that an effective safety culture can make to the control of their ongoing operational costs and the efficiency of their ongoing operations.

There is no consistent and visible prescriptive formula for developing a strong safety culture, the choice of practices for developing an improved safety culture should take account of the existing national and organizational culture in order to ensure effective implementation.

This paper offered a detailed discussion about safety culture from many different point of views, such as characteristics and requirements of strong safety culture. Also, as regulator, a special focus is given to relation between regulatory body and the NPPs owner organization. The impact of regulatory body safety culture on the organization culture on strengthening and promoting the organization's safety culture is explained. A regulator should keep a good and balanced relation with the operator to promote not to preclude safety. Both regulator and operator should unify their efforts towards one and only one target, keep and promoting safety.

\section{References}

[1] "Lessons Learned from the Fukushima Nuclear Accident for Improving Safety and Security of U.S. Nuclear Plants, Nuclear and Radiation Studies" Board, Division on Earth and Life Studies - 2014 - Political Science people and the environment (INPO, 2013, p. iv)

https://books.google.com.eg/books?isbn=0309272564.
[2] International Atomic Energy Agency, "Safety culture in nuclear installations" - IAEA Publications wwwpub.iaea.org/MTCD/publications/PDF/te_1329_web.pdf.

[3] International Atomic Energy Agency, Safety Culture, Safety Series No. 75 -INSAG-4 IAEA, Vienna, Austria 1991.

[4] International Atomic Energy Agency, Developing Safety Culture in Nuclear Activities, Practical Suggestions to Assist Progress, IAEA Safety Reports Series No. 11, IAEA, Austria, Vienna, 1998.

[5] International Atomic Energy Agency, Summary Report on the Post Accident Review Meeting on the Chernobyl Accident, Safety Series No.75 INSAG-1, IAEA, Vienna, 1986.

[6] International Atomic Energy Agency, Basic Safety Principles for Nuclear Power plants, Safety Series No. 75- INSAG-3, (revised as INSAG-12), IAEA, Vienna, Austria, Dec 9, 2014.

[7] International Atomic Energy Agency, ASCOT Guidelines, IAEA- TEC DOC -860, Vienna, 1996.

[8] Rasa Ptasekaite, "The Role of the Regulator: Nuclear Safety and Nuclear Safety Culture", Dissertation for the International, School of Nuclear Law, Montpellier 2011.

[9] International Atomic Energy Agency, Experience with Strengthing Safety Culture in Nuclear power plants, IAEATEC DOC 821, Vienna, 1995.

[10] "Role of Regulator in Promoting Safety Culture", Sallam H. www.ijird.com May, 2014 Vol 3 Issue 5.

[11] Kolb. D., Experiential Learning, Prentice- Hall, Englewood Cliffs, NI (1984).

[12] Samia M. Rashad, Lessons Learned From Selected Nuclear Radiological and Industrial Accidents, proceedings of a Seminar on Safety, Quality and Risk Culture organized by Atomic Energy Authority and Institute of statistical Research and Studies, Cairo university, Cairo, Egypt, 1996. 